CORRESPONDENCE

LETTER TO THE EDITOR

\title{
SUICIDE IS A CONFOUNDER IN POSTMORTEM STUDIES ON DEPRESSION
}

\section{Dear Editor,}

Over the past decade, pioneering studies have reported changes in various genes and proteins in post-mortem brain samples of patients who had suffered from major depression disorder (MDD) (e.g. Cobb (1); et al Clark et al (2); Weissmann et al (3); Kunii et al (4); Reinhart et al (5); Turecki et al (6); Martins-de-Souza et al (7); Kekesi et al (8); Shelton et al (9); Klempan et al (10); Sequira et al (11); Feyissa et al (12); Poulter et al (13); Bach et al (14); see also Almeida et al (15); Lutz et al (16); Gittins et al (17) and Table 1). Even though clear inferences were made based on these results regarding underlying disease mechanisms, it is also apparent that the results differ clearly between different studies, often even in opposite directions, and even if the patient groups had been carefully matched for factors like age, gender and post-mortem delay. As a result, it has been difficult to distil a uniform picture from these unique human brain studies, let alone obtain a better insight in the neurobiological changes underlying MDD or suicide.

Based on a careful review of the literature (see Table 1) and on our own studies (18-20), we here propose that part of this confusion results from the fact that suicide has always been considered a symptom, and thus an integral part of MDD (21), whereas in these studies, the group of depressed 
patients contained often both, (MDD-S) and patients without suicide (MDD-NS). As a result, post-mortem studies that claimed to have determined molecular alterations in relation to MDD, had in fact often selected depressed patients that had died all, or for a major part, from suicide. They were commonly compared to control subjects without any psychiatric disorder, thereby disregarding the fact that suicide per se may have influenced gene expression in their postmortem brains as well, and may thus have confounded earlier findings that were interpreted as being specific for depression alone. Secondly, studies that claimed to have shown changes in relation to suicide, had generally compared cases who had committed suicide to matched controls without any psychiatric disorder, thereby disregarding the fact that suicide occurs in many psychiatric disorders and conditions, including mood and anxiety disorders, but also in schizophrenia, personality- or substance abuse disorders $(21,22)$.

To date, very few papers have attempted to study (molecular) neurobiological differences between suicide and depression separately. Turecki's group attempted to disentangle alterations due to either depression or suicide by comparing three groups: 1) patients who committed suicide during an episode of MDD, 2) suicide victims without a lifetime history of MDD, and 3) age-matched controls with no history of suicidal behavior, and without a major psychiatric diagnosis. They found indeed several differentially expressed genes in the hippocampus when comparing the two groups of suicide completers (23) 2009). Follow-up studies showed that all differentially expressed GABA-related genes were clearly up-regulated in suicide completers who suffered from MDD, but down-regulated in suicide completers without a history of MDD, suggesting a depression-specific effect on GABAergic genes (11). Pandey's group tried to divide the suicide group into two subgroups: one with depression and one with other psychiatric disorders. In this way they attempted to examine if there was an influence from depression factor on their suicide study (24). Sibille's 
group took the suicide victims in their depression study into consideration through statistics (25). We applaud this approach and a next step, ideally, would be to assess which molecular changes relate to suicide per se, i.e. independent of MDD, and a fourth comparison group that had suffered from MDD, but did not die from suicide, would be very informative in this respect.

Studies on MDD patients show clear differences, when suicide is being taken in account. Gray et al. have e.g. analyzed MDD-S and MDD-NS patients and found increased dorsolateral prefrontal cortex expression of several glutamate receptor-related genes in MDD subjects who died by suicide (26). Also the use of other approaches illustrates the importance of distinguishing suicide from MDD per se; e.g. Miller et al., used PET imaging to study live subjects comparing: 1) controls without a brain disorder, 2) major depressed patients without a history of suicide attempts, and 3) major depressed patients with a history of suicide attempts (27). They found that only the suicide attempters had lower serotonin transporter levels. However, a group of patients (depressed or otherwise) that had actually died of suicide was lacking, for obvious reasons. Also in our own studies, we found an enhanced expression of GABA/glutamate-related genes in the anterior cingulate cortex of MDD-S patients, while transcript levels in a MDD-NS group were decreased with opposite alterations being found in the dorsolateral prefrontal cortex (20). Furthermore, metaanalysis showed it is possible to distinguish suicidal from non-suicidal patients based on peripheral cytokine levels (28). Thus, in order to improve our understanding of the underlying neurobiological mechanisms and molecular signatures of psychiatric disorders, it is important to realize that earlier postmortem studies may have analyzed mixed groups, and combined patients with and without suicide attempts. This may have overlooked brain changes specific for suicide per se and thereby obscured a correct interpretation of the true changes occurring in depression alone. 
We therefore propose that in future postmortem studies on mood disorders, ideally, at least four groups are distinguished: 1) age-matched controls without a brain disorder, 2) depressed patients who did not commit suicide and did not have suicidal ideations or attempts, but died from other causes, 3) depressed patients with suicide attempts or ideations, but who died from other causes, and 4) depressed patients with accomplished suicide. While brain material for such studies may not be easy to collect, it will form a very important step towards a better understanding of the true molecular changes at play in MDD per se, and from there, may help develop a better risk assessment, patient stratification and future treatment strategies for the two severe, life threatening, and likely inherently different, psychiatric disorders MDD with, and MDD without suicide.

Juan Zhao ${ }^{1,}$ Paul J. Lucassen ${ }^{2}$ and Dick F Swaab ${ }^{1}$

${ }^{1}$ Netherlands Institute for Neuroscience, an Institute of the Royal Netherlands Academy of Arts and Sciences, Amsterdam, the Netherlands;

${ }^{2}$ Swammerdam Institute for Life Sciences, Center for Neuroscience, University of Amsterdam, The Netherlands.

1. Cobb JA, O'Neill K, Milner J, Mahajan GJ, Lawrence TJ, May WL, et al. (2016): Density of GFAPimmunoreactive astrocytes is decreased in left hippocampi in major depressive disorder. Neuroscience. 316:209-220.

2. Clark SM, Pocivavsek A, Nicholson JD, Notarangelo FM, Langenberg P, McMahon RP, et al. (2016): Reduced kynurenine pathway metabolism and cytokine expression in the prefrontal cortex of depressed individuals. Journal of psychiatry \& neuroscience : JPN. 41:386-394.

3. Weissmann D, van der Laan S, Underwood MD, Salvetat N, Cavarec L, Vincent L, et al. (2016): Region-specific alterations of A-to-I RNA editing of serotonin $2 \mathrm{c}$ receptor in the cortex of suicides with major depression. Transl Psychiatry. 6:e878.

4. Kunii Y, Zhang W, Xu Q, Hyde TM, McFadden W, Shin JH, et al. (2015): CHRNA7 and CHRFAM7A mRNAs: co-localized and their expression levels altered in the postmortem dorsolateral prefrontal cortex in major psychiatric disorders. The American journal of psychiatry. 172:1122-1130. 
5. Reinhart V, Bove SE, Volfson D, Lewis DA, Kleiman RJ, Lanz TA (2015): Evaluation of TrkB and BDNF transcripts in prefrontal cortex, hippocampus, and striatum from subjects with schizophrenia, bipolar disorder, and major depressive disorder. Neurobiology of disease. 77:220-227.

6. $\quad$ Turecki G (2014): The molecular bases of the suicidal brain. Nat Rev Neurosci.

7. Martins-de-Souza D, Guest PC, Harris LW, Vanattou-Saifoudine N, Webster MJ, Rahmoune H, et al. (2012): Identification of proteomic signatures associated with depression and psychotic depression in post-mortem brains from major depression patients. Transl Psychiatry. 2:e87.

8. Kekesi KA, Juhasz G, Simor A, Gulyassy P, Szego EM, Hunyadi-Gulyas E, et al. (2012): Altered functional protein networks in the prefrontal cortex and amygdala of victims of suicide. PloS one. 7:e50532.

9. Shelton RC, Claiborne J, Sidoryk-Wegrzynowicz M, Reddy R, Aschner M, Lewis DA, et al. (2011): Altered expression of genes involved in inflammation and apoptosis in frontal cortex in major depression. Molecular psychiatry. 16:751-762.

10. Klempan TA, Sequeira A, Canetti L, Lalovic A, Ernst C, ffrench-Mullen J, et al. (2009): Altered expression of genes involved in ATP biosynthesis and GABAergic neurotransmission in the ventral prefrontal cortex of suicides with and without major depression. Molecular psychiatry. 14:175-189.

11. Sequeira A, Mamdani F, Ernst C, Vawter MP, Bunney WE, Lebel V, et al. (2009): Global brain gene expression analysis links glutamatergic and GABAergic alterations to suicide and major depression. PloS one. 4:e6585.

12. Feyissa AM, Chandran A, Stockmeier CA, Karolewicz B (2009): Reduced levels of NR2A and NR2B subunits of NMDA receptor and PSD-95 in the prefrontal cortex in major depression. Progress in neuro-psychopharmacology \& biological psychiatry. 33:70-75.

13. Poulter MO, Du L, Weaver IC, Palkovits M, Faludi G, Merali Z, et al. (2008): GABAA receptor promoter hypermethylation in suicide brain: implications for the involvement of epigenetic processes. Biological psychiatry. 64:645-652.

14. Bach H, Huang YY, Underwood MD, Dwork AJ, Mann JJ, Arango V (2014): Elevated serotonin and 5-HIAA in the brainstem and lower serotonin turnover in the prefrontal cortex of suicides. Synapse. 68:127-130.

15. Almeida D, Turecki G (2016): A Slice of the Suicidal Brain: What Have Postmortem Molecular Studies Taught Us? Current psychiatry reports. 18:98.

16. Lutz PE, Mechawar N, Turecki G (2017): Neuropathology of suicide: recent findings and future directions. Molecular psychiatry. 22:1395-1412.

17. Gittins RA, Harrison PJ (2011): A morphometric study of glia and neurons in the anterior cingulate cortex in mood disorder. Journal of affective disorders. 133:328-332.

18. Zhao J, Qi XR, Gao SF, Lu J, van Wamelen DJ, Kamphuis W, et al. (2015): Different stressrelated gene expression in depression and suicide. J Psychiatr Res. 68:176-185.

19. Zhao J, Verwer RW, van Wamelen DJ, Qi XR, Gao SF, Lucassen PJ, et al. (2016): Prefrontal changes in the glutamate-glutamine cycle and neuronal/glial glutamate transporters in depression with and without suicide. $J$ Psychiatr Res. 82:8-15.

20. Zhao J, Verwer RWH, Gao SF, Qi XR, Lucassen PJ, Kessels HW, et al. (2018): Prefrontal alterations in GABAergic and glutamatergic gene expression in relation to depression and suicide. $J$ Psychiatr Res. 102:261-274.

21. Aleman A, Denys D (2014): Mental health: A road map for suicide research and prevention. Nature. 509:421-423.

22. Hawton K, van Heeringen K (2009): Suicide. Lancet. 373:1372-1381.

23. Sequeira A, Klempan T, Canetti L, ffrench-Mullen J, Benkelfat C, Rouleau GA, et al. (2007):

Patterns of gene expression in the limbic system of suicides with and without major depression. Molecular psychiatry. 12:640-655.

24. Dwivedi Y, Rizavi HS, Zhang H, Roberts RC, Conley RR, Pandey GN (2010): Modulation in activation and expression of phosphatase and tensin homolog on chromosome ten, Akt1, and 3phosphoinositide-dependent kinase 1: further evidence demonstrating altered phosphoinositide 3-kinase signaling in postmortem brain of suicide subjects. Biological psychiatry. 67:1017-1025.

25. Scifo E, Pabba M, Kapadia F, Ma T, Lewis DA, Tseng GC, et al. (2018): Sustained Molecular Pathology Across Episodes and Remission in Major Depressive Disorder. Biological psychiatry. 83:81-89. 
26. Gray AL, Hyde TM, Deep-Soboslay A, Kleinman JE, Sodhi MS (2015): Sex differences in glutamate receptor gene expression in major depression and suicide. Molecular psychiatry. 20:10571068.

27. Miller JM, Hesselgrave N, Ogden RT, Sullivan GM, Oquendo MA, Mann JJ, et al. (2013): Positron emission tomography quantification of serotonin transporter in suicide attempters with major depressive disorder. Biological psychiatry. 74:287-295.

28. Black C, Miller BJ (2015): Meta-Analysis of Cytokines and Chemokines in Suicidality:

Distinguishing Suicidal Versus Nonsuicidal Patients. Biological psychiatry. 78:28-37. 